\title{
Effect of drying and extrusion processing on physical and nutritional characteristics of bilberry press cake extrudates
}

\author{
Evelina Höglund $^{\mathrm{a}, *}$, Lovisa Eliasson ${ }^{\mathrm{a}}$, Gabriel Oliveira ${ }^{\mathrm{b}}$, Valérie L. Almli ${ }^{\mathrm{c}}$, Nesli Sozer ${ }^{\mathrm{d}}$, \\ Marie Alminger ${ }^{\mathrm{b}}$ \\ ${ }^{\text {a }}$ RISE Research Institutes of Sweden, Agrifood and Bioscience, Box 5401, 40229 Göteborg, Sweden \\ ${ }^{\mathrm{b}}$ Chalmers University of Technology, Department of Biology and Biological Engineering, 41296 Göteborg, Sweden \\ ${ }^{\mathrm{c}}$ Nofima AS, P.O. Box 210, 1431 Ass, Norway \\ ${ }^{\mathrm{d}}$ VTT Tecnhical Research Centre of Finland Ltd, Tietotie 2, Espoo, Finland
}

\begin{abstract}
A B S T R A C T
Mild drying and extrusion processing of side streams from berry juice production can enable retention of valuable compounds in the food chain and reduce waste production. The aim of this study was to evaluate the applicability of using hot air (HA) and microwave assisted hot air (MWHA) drying combined with extrusion for conversion of bilberry press cake into value-added extruded food products. Bilberry press cake was dried at $40{ }^{\circ} \mathrm{C}$ by HA and MWHA drying to a moisture content of $17 \mathrm{~g} / 100 \mathrm{~g}$. A twin screw extruder (average feed rate $72 \mathrm{~g} /$ min, temperature profile $135-128-89-69^{\circ} \mathrm{C}$ ) was used to extrude products containing organic wholegrain rye flour and $10 \%$ or $25 \%$ dried bilberry press cake powder. A consumer panel $(n=15)$ evaluated four extrudates on hedonic and Just-About-Right (JAR) scales, with a main focus on texture properties. The results indicate that different drying techniques implied a difference in processing time (40\% reduction with MWHA drying). However, the retention of total phenolics and physical characteristics of extruded snacks containing bilberry powders were independent of drying techniques. In sum, powder of bilberry press cake can be incorporated in cereal based extruded snacks with enhanced phenolic content and potential for palatable sensory properties.
\end{abstract}

\section{Introduction}

Berries are perishable seasonal products and the shelf-life of fresh berries is normally short. In general, half of fresh fruit and vegetable production is lost before consumption (Gustavsson \& Stage, 2011). To increase the commercial value and reduce waste it is reasonable to process berries into more stable products. Drying is a commonly used preservation method for fruits and vegetables, enabling extended shelf life as well as formulation of fruit and vegetable based products (Jangam, Law, \& Mujumdar, 2010). In the juice industry, the press cake left after juice extraction may account for approximately $30 \mathrm{~g} / 100 \mathrm{~g}$ of the dry solids of the berries (Kryeviciute, Kraujalis, \& Venkutonis, 2016). Hence, the side streams from berry juice production may be upgraded into value-added products to achieve sustainable production chains. Grzelak-Blaszczyk, Karlinska, Grzeda, Roj, and Kolodziejczyk (2017) studied utilization of strawberry press cake and concluded that it can be used as a food additive high in protein, fibre and polyphenol content which contributes to improved sustainability of the fruit industry. Bilberries (Vaccinium myrtillus L.), wild growing berries in northern Europe and North America, are naturally rich in polyphenols such as anthocyanins (Mikulic-Petkovsek, Schmitzer, Slatnar, Stampar, \& Veberic, 2015) which have been reported to contribute to prevention of a number of diseases such as type 2 diabetes and cardiovascular diseases (Pojer, Mattivi, Johnson, \& Stockley, 2013). After extraction, the press cake is composed of mainly skins and seed and with them a large part $(58 \mathrm{~g} / 100 \mathrm{~g})$ of the phenolic compounds present in the berries (Dinkova et al., 2012). Dried press cakes from juice production also contains dietary fibre (ca $68 \mathrm{~g} / 100 \mathrm{~g}$ ), protein (ca $15 \mathrm{~g} / 100 \mathrm{~g}$ ) and lipids (Struck, Plaza, Turner, \& Rohm, 2016). Berries and berry press cake can be dried and milled into stable and convenient powder products, which can be further used as ingredients in the food industry (Figuerola, 2007), such as in extruded snacks and cereals. The addition of bilberry press cake to extruded cereals and snacks brings added flavour as well as higher nutritional value, as the majority of the existing extruded snacks on the market have high carbohydrate, sugar and lipid content and poor nutritional value.

The choice of processing methods and conditions has large impact on the characteristics of fruit and vegetable products such as

\footnotetext{
* Corresponding author.

E-mail address: evelina.hoglund@ri.se (E. Höglund).
} 
microstructure, flavour and micronutrient retention, textural properties etc (Van Buggenhout et al., 2012). Hot air (HA) drying is a technique commonly used for berry preservation. Microwave assisted hot air (MWHA) drying, on the other hand, uses microwaves together with hot air to increase drying efficiency and decrease drying time. The drying mechanism is different from HA drying since the microwaves penetrate the product and create internal temperature increase. The latter may affect the microstructure of the dried products and hence, flavour and micronutrient retention. Drying processes using different methods have previously been reported to have significant effects on the degradation of bioactive compounds in berries (Zielinska \& Michalska, 2016). Dried berry materials may be further used as food ingredients in for example extruded products. Extrusion processing is a continuous short time high shearing technology, which consists of subsequent series of mixing, forming, puffing and drying processes. It is a useful tool to design expanded ready-to-eat foods (snacks, cereals, etc.) or to modify food ingredients. The extrusion process leads to irreversible changes such as denaturation of proteins and formation of starch-lipid, protein-lipid and protein-protein complexes (Sozer \& Poutanen, 2013, pp. 256-272). The aim of this study was to evaluate the applicability of pre-treatments using HA and MWHA drying combined with extrusion for conversion of bilberry press cake into value-added extruded food products.

\section{Materials and methods}

\subsection{Raw material}

Bilberry (Vaccinium myrtillus L.) press cake, produced by cold pressing without enzymatic treatment, was supplied by Kalix Syltfabrik $\mathrm{AB}$ (Kalix, Sweden). The bilberry press cake contained skin and seeds and had a moisture content of $75.6 \mathrm{~g} / 100 \mathrm{~g} \pm 0.5 \mathrm{~g} / 100 \mathrm{~g}$, and was stored in the dark at $-40{ }^{\circ} \mathrm{C}$ until use. The press cake was thawed in closed, opaque containers at $20^{\circ} \mathrm{C}$ overnight $(15 \mathrm{~h})$ prior to drying.

\subsection{Drying and milling}

Bilberry press cake was dried at $40^{\circ} \mathrm{C}$ in the absence of light by HA drying and MWHA drying to a moisture content of $17 \mathrm{~g} / 100 \mathrm{~g}$. The target moisture content of $17 \mathrm{~g} / 100 \mathrm{~g}$ was chosen to achieve a powder that was dry enough to be included in an extrusion formula, but at the same time the drying time was kept as short as possible to limit energy consumption in a manufacturing process and avoid extensive losses of phenolic compounds and aroma. After drying, the material was stored in sealed polyamide/polyethylene plastic pouches in the dark at $-40{ }^{\circ} \mathrm{C}$ until milling. In order to obtain enough dried material for extrusion trials HA and MWHA drying was carried out in two batches, conducted on two subsequent days. After drying, the batches were mixed before milling. The HA drying was realized in a conventional hot air oven (Garomat 142 Electrolux, Stockholm, Sweden), where two trays (size $21 \times 30 \mathrm{~cm}$ ) with approximately $1250 \mathrm{~g}$ bilberry press cake in each were placed in the middle of the oven. The fan of the oven created an air velocity of $6.1 \mathrm{~m} / \mathrm{s}$. The MWHA drying was performed according to the procedure and system described by Kerbstadt et al. (2015). In brief, $1250 \mathrm{~g}$ bilberry press cake was loaded in the microwave cavity (TIVOX Automation AN, Tidaholm, Sweden) that was connected to an air heating unit with a fan (HONEYWELL INU control AB, Borås, Sweden) resulting in an air speed of $0.8 \mathrm{~m} / \mathrm{s}$ in the middle of the cavity. The microwave power, of maximum $1000 \mathrm{~W}$, was supplied by Magdrive1400 (Tivox, Tidaholm, Sweden), with wavelength of approximately $0.12 \mathrm{~m}$ at a frequency of $2450 \mathrm{MHz}$. To keep the desired treatment temperature, the microwave power was regulated automatically by the software MagDrive c3.1 (Tivox Maskin AB, Tidaholm, Sweden) dependent on the sample temperature that was measured by fibre optic temperature probes (Neoptix Inc., Quebec, Canada). The dried press cake was milled using a coffee mill (Ascaso i-I, Ascaso, Barcelona, Spain). The milled material was stored in sealed polyamide/ polyethylene pouches in the dark at $-40{ }^{\circ} \mathrm{C}$ until further analysis or shipment to the sites for micronutrient analysis or extrusion.

\subsection{Moisture content, water activity and particle size distribution}

Moisture content of bilberry press cake, dried material, and dried and milled material were measured gravimetrically in a vacuum oven (Sanyo Gallenkamp, Loughborough, UK). The analysis was done in triplicates by drying of approx. $2.5 \mathrm{~g}$ sample at $80^{\circ} \mathrm{C}$ and $900 \mathrm{mbar}$ in aluminum dishes until constant weight. The water activity was measured in triplicates using an Aqua Lab 4 TE (Decagon Devices, Pullman, Washington, USA). Determination of the particle size distribution of the powder was done by a vibratory sieve-shaker (Analysette 3, FRITSCH, Idar-Oberstein, Germany) with sieves of mesh sizes $250 \mu \mathrm{m}, 500 \mu \mathrm{m}$, $710 \mu \mathrm{m}$ and $1250 \mu \mathrm{m}$. The sieve shaking was run for $10 \mathrm{~min}$ at an amplitude of $1.5 \mathrm{~mm}$ and with an interval of $10 \mathrm{~s}$. Particle size analysis was done in duplicate with about $20 \mathrm{~g}$ of powder each time.

\subsection{Extrusion}

Extruded puffs were prepared by substituting organic wholegrain rye flour (Fazer Mills, Finland) with $10 \%$ and $25 \%$ bilberry press cake powders. A reference extruded puff was prepared by using only organic wholegrain rye flour. A twin screw extruder (APV MPF 19/25, Baker Perkins Group Ltd, Peterborough, UK) with an average feed rate of $72 \mathrm{~g} / \mathrm{min}$ and temperature profile of $135-128-89-69^{\circ} \mathrm{C}$ was used, together with a co-rotating twin screw feeder (K-Tron Soder, Niederlenz, Switzerland). The die diameter and screw speed were $3 \mathrm{~mm}$ and $360 \mathrm{rpm}$ for all extrusion trials. Water feed rate was set to $3.7 \mathrm{~g} / \mathrm{min}$ only for wholegrain rye flour and the rest of samples were extruded without any water addition as the in situ moisture content of berry powder was sufficient for extrusion processing. The moisture content of the feed materials were $11 \pm 0.07 \mathrm{~g} / 100 \mathrm{~g}, 11.6 \pm 0.02 \mathrm{~g} / 100 \mathrm{~g}$ and $12.5 \pm 0.01 \mathrm{~g} / 100 \mathrm{~g}$, for organic wholegrain rye flour, wholegrain rye flour supplemented with $10 \%$ and $25 \%$ billberry press cake powder, respectively. Specific mechanical energy (SME) is an important process parameter used to describe processing conditions and was calculated with Eq. (1).

(Hu, Hsieh, \& Huff, 1993):

$S M E\left(\frac{k W h}{k g}\right)=\frac{w}{w_{r}} * \frac{\tau}{100} * \frac{Z_{r}}{Q}$

where $\omega$ is the screw speed (in rotations per minute, rpm), $\omega_{r}$ is the maximum screw speed of the extruder used $(500 \mathrm{rpm}), \tau$ is the torque (in percent), $Z_{\mathrm{r}}$ is the maximum power capacity of the extruder $(2 \mathrm{~kW})$ and $\mathrm{Q}$ is the feed rate (in kilogram per hour). Extruded products were collected continuously from the die exit after manually cutting to a $20 \mathrm{~cm}$ length with scissors and dried immediately in an oven for $10 \mathrm{~min}$ at $100^{\circ} \mathrm{C}$. Extrusion processing was performed in duplicate.

\subsection{Stereomicroscopy}

For the stereomicroscope imaging of the radial cross-sections of the extrudates, the samples were cut into $10 \mathrm{~mm}$ pieces with an electric saw (Power ST-WBS800, Taiwan Sheng Tsai Industrial Co. Ltd., Taiwan) and examined under a SteREO Discovery. V8 stereomicroscope with an Achromat S $0.5 \times$ objective (Carl Zeiss MicroImaging $\mathrm{GmbH}$, Göttingen, Germany) and imaged using a DP-25 single chip colour CCD camera (Olympus Life Science Europa GmbH, Hamburg, Germany) and the Cell^ $\mathrm{P}$ imaging software (Olympus).

\subsection{Macrostructural analysis}

Length and diameter in three different points of each sample were measured using a vernier caliper and the average diameters of the 
samples were obtained. The measurements were made from 20 replicates from each extrusion treatments using the method described by Alam et al. (2014).

Expansion rate was calculated with Eq. (2):

Expansion rate $(\%)=\frac{D_{e}}{D_{d}} \times 100 \%$

where $D_{e}$ is the average diameter measured at three different points of the extrudate sample $(\mathrm{mm})$ and $D_{d}$ is the diameter of the die $(3 \mathrm{~mm})$. Specific length was calculated with Eq. (3):

Specific length $(\mathrm{m} / \mathrm{kg})=\frac{L_{e}}{m_{e}}$

where $L_{e}$ is the length of the extrudate sample (m) and $m_{e}$ is the mass of the sample (kg). Piece density was calculated with Eq. (4):

Piece density $\left(\mathrm{kg} / \mathrm{m}^{3}\right)=\frac{4 \times m_{e}}{\pi \times\left(D_{e}\right)^{2} \times L_{e}}$

where $\mathrm{m}_{\mathrm{e}}$ is the mass of the sample $(\mathrm{kg}), D_{e}$ is the average diameter measured at three different points of the extrudate sample (m) and $L_{e}$ is the length of the extrudate sample (m).

\subsection{Textural properties}

Mechanical properties of extrudates were analyzed by uniaxial compression test using a texture analyser (Texture Analyser TA-HDi, HD3071, Stable Micro Systems, United Kingdom) equipped with a $30 \mathrm{~kg}$ load cell and a cylindrical $36 \mathrm{~mm}$ aluminium probe. Samples of $10 \mathrm{~mm}$ length were cut and equilibrated at a relative humidity (RH) of $43 \%$ at $21{ }^{\circ} \mathrm{C}$. The samples were deformed at $70 \%$ strain with a test speed of $1 \mathrm{~mm} / \mathrm{s}$. The force-deformation (f-d) curve was obtained to assess the mechanical characteristics of the extrudate samples. Each measurement was performed with 20 replicates. Texture Exponent software v.5.1.2.0 (Stable Micro Systems, UK) was used to obtain values of actual and smoothed curve length, area under the f-d curve (A), number of peaks, crushing force (A/distance of compression) and hardness $\left(F_{\max }\right)$. Different approaches were used to describe the crispiness of extrudates, such as crispiness work ( $C w$, Eq. (5)) and crispiness index (Ci, Eq. (6)). High crispiness was accompanied by low $C w$ and high $C i$ value, whereas low crispiness corresponded to high $\mathrm{Cw}$ and low $\mathrm{Ci}$ value (Alam et al., 2014; Sibakov et al., 2015).

Crispiness work was calculated with Eq. (5) (Van Hecke, Allaf, \& Bouvier, 1998):

$C_{w}(\mathrm{~N} \mathrm{~mm})=\frac{A}{N}$

where $A$ is the area under the $\mathrm{f}-\mathrm{d}$ curve $(\mathrm{N} \mathrm{mm})$ and $\mathrm{N}$ is the number of peaks.

Crispiness index was calculated with Eq. (6) (Heidenreich, Jaros, Rohm, \& Ziems, 2004):

$C_{i}=\frac{L_{N}}{A \times F_{\text {mean }}}$

where $L_{N}$ is the normalized curve length (length of actual curve $/ F_{\max }$ ), $A$ is the area under the $\mathrm{f}$ - $\mathrm{d}$ curve $(\mathrm{N} \mathrm{mm})$ and $F_{\text {mean }}$ is the sum of the actual force values divided by the number of peaks $(\mathrm{N})$.

\subsection{Dietary fibre analysis of extrudates}

Insoluble, soluble and total dietary fibre contents of extrudates were determined according to Megazyme rapid integrated total dietary fibre assay procedure (K-RINTDF 09/16 Megazyme, Ireland) combining key attributes of AOAC Official Methods 2002.02, 985.29, 991.43 and 2001.03. Duplicate test portions of each sample $(1 \mathrm{~g})$ were incubated with pancreatic $\alpha$-amylase (PAA) and amyloglucosidase (AMG) for $4 \mathrm{~h}$ at $37^{\circ} \mathrm{C}$, thus non-resistant starch was solubilized and hydrolysed into D-glucose and maltose. The reaction was terminated by adjusting $\mathrm{pH}$ to 8.2 and heating to $95^{\circ} \mathrm{C}$ to inactivate both PAA and AMG. Proteins in the samples were denaturated and digested with protease. After this step soluble, insoluble and accordingly total dietary fibre contents were determined as described in detail in the Megazyme assay procedure.

\subsection{Total phenolic content}

The extractions and measurements of phenolics were made according to methods for extraction and analyses described by Howard, Clark, and Brownmiller (2003) and Barnes, Nguyen, Shen, and Schug (2009), with some modifications. Frozen extruded snacks consisting of rye flour with and without added bilberry powders were freeze-dried and ground to smallest possible particle size using a mortar. Triplicate samples $(0.2 \pm 0.015 \mathrm{~g})$ were extracted in screw-cap tubes with methanol/water/Trifluoroacetic acid (70:30:1 (v/v)). The samples were vortexed for $15 \mathrm{~s}$ followed by sonication for $2 \times 5 \mathrm{~min}$ and incubation for $30 \mathrm{~min}\left(60^{\circ} \mathrm{C}, 100 \mathrm{rpm}\right)$. After cooling on ice the tubes were vortexed again for $15 \mathrm{~s}$ and centrifuged at $5000 \mathrm{~g}$ for $5 \mathrm{~min}$ at $4{ }^{\circ} \mathrm{C}$. Supernatants were collected and the remaining pellets were re-dissolved in $5 \mathrm{ml}$ extraction solution. After vortexing for $15 \mathrm{~s}$ and sonication $(2 \times 5 \mathrm{~min})$ and centrifugation $\left(5000 \mathrm{~g}, 5 \mathrm{~min}, 4^{\circ} \mathrm{C}\right)$ the 2 supernatants were combined. The phenolic content of the extracts was determined spectrophotometrically with Folin-Ciocalteu's reagent against a standard curve of gallic acid and measuring absorbance at $765 \mathrm{~nm}^{2}$ on a Safire plate reader (TECAN) with Magellan software. The results are expressed in mg gallic acid equivalents in $g$ of dry weight (mg GAE/g). The dry weight was determined by duplicate measurements on a dry matter analysis scale.

\subsection{Consumer evaluation}

The four extruded samples containing bilberry powder were evaluated using a convenience consumer panel of 15 participants, three men and 12 women between 20 and 60 years old recruited among colleagues external to the project at Chalmers University of Technology. This panel was used with the aim to perform a feasibility study, answering the needs of early stages in a product development process. The low number of consumers involved may not be used to draw conclusions from a representative statistical point of view, but to provide initial insights on the perceived texture variations and palatability of the extruded samples. The samples were coded with 3-digit random numbers and presented together with a score-card in a randomized balanced order to each participant (MacFie, Bratchell, Greenhoff, \& Vallis, 1989). For each sample, a 9-point hedonic rating scale $(1=$ extremely bad, $5=$ neither good nor bad, $9=$ extremely good) was first used to evaluate overall liking, appearance, taste and texture. Then, a Just-AboutRight (JAR) scale (Lawless \& Heymann, 2010) was used to provide a subjective quantitative evaluation of specific texture attributes: crispness, porosity, stickiness and hardness (1: Far from [crispy] enough, 5: Just about right, 9: Far too [crispy]). Drinking water was provided for mouth rinsing between samples. All samples were presented in blind condition, i.e. without any information about processing or ingredients content.

\subsection{Statistical methods}

Multiple comparison tests using Tukey's honest significant difference criterion was performed to assess if there were any statistically significant differences between measurement data in Fig. 1 and Tables 1 and 2. A value of $p<0.05$ was considered statistically significant. For the sensory results the data were analyzed by means of analysis of variance (ANOVA) in The Unscrambler X 10.3 (CAMO Software AS, Norway). The ANOVA model tested the main effects of factors drying process and bilberry powder content on the consumer responses. As 


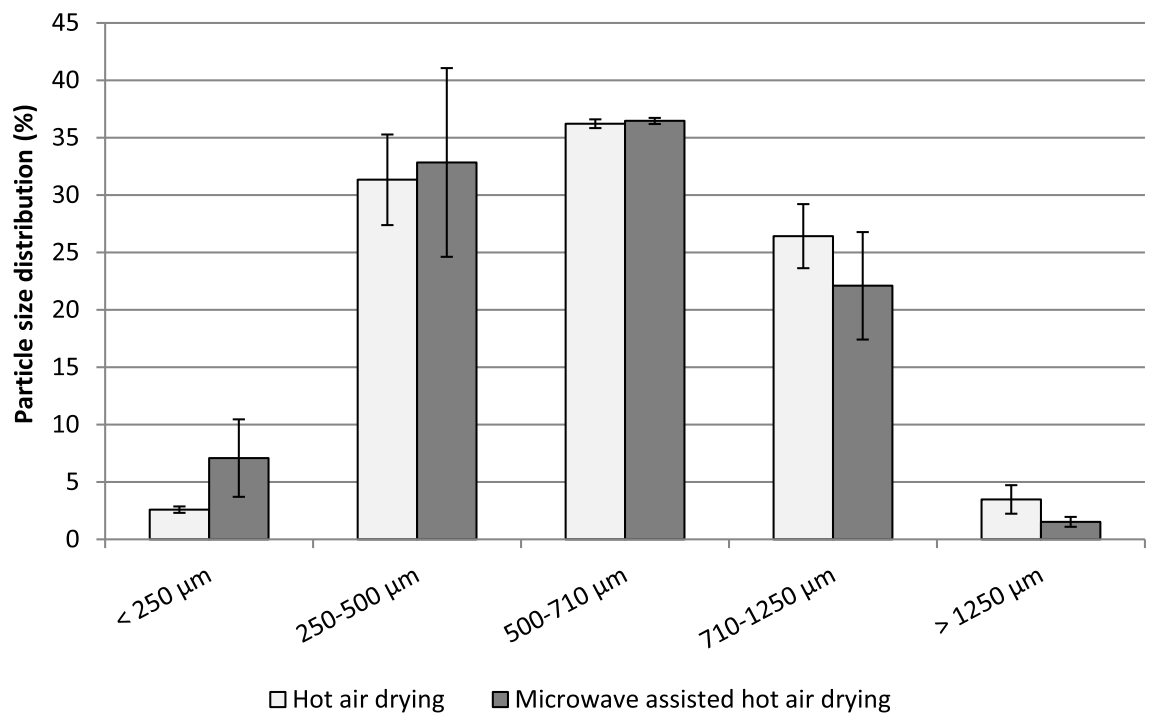

Fig. 1. Particle size distribution of the dried and milled bilberry press cake. No values were significantly different $(\mathrm{p}<0.05)$ based on Tukey's test.

Table 1

Characteristics of the bilberry press cake (mean \pm standard deviation). Values followed by the same letter in the same line were not significantly different $(\mathrm{p}<0.05)$ based on Tukey's test.

\begin{tabular}{llll}
\hline $\begin{array}{l}\text { Bilberry material } \\
\text { characteristics }\end{array}$ & $\begin{array}{l}\text { Moisture content } \\
(\mathrm{g} / 100 \mathrm{~g})\end{array}$ & Water activity & $\begin{array}{l}\text { Total phenolic } \\
\text { content }(\mathrm{mg} / \mathrm{g} \text { DW })\end{array}$ \\
\hline $\begin{array}{l}\text { Press cake } \\
\text { Hot air drying, not } \\
\text { milled }\end{array}$ & $\begin{array}{l}75.6 \pm 0.9 \pm 2.1^{\mathrm{b}} \\
\text { Microwave hot air }\end{array}$ & - & $216.1^{\mathrm{a}} \pm 5.3$ \\
$\quad$ drying, not & $17.8 \pm 1.0^{\mathrm{b}}$ & - & $60.4^{\mathrm{b}} \pm 2.6$ \\
$\quad$ milled & & & $58.4^{\mathrm{b}} \pm 0.3$ \\
$\begin{array}{l}\text { Hot air drying, milled } \\
\text { Microwave hot air } \\
\text { drying, milled }\end{array}$ & $16.9 \pm 0.1^{\mathrm{b}}$ & $0.757^{\mathrm{a}} \pm 0.003$ & $61.9^{\mathrm{b}} \pm 0.5$ \\
& $17.0 \pm 0.2^{\mathrm{b}}$ & $0.755^{\mathrm{a}} \pm 0.004$ & $62.0^{\mathrm{b}} \pm 2.8$ \\
\hline
\end{tabular}

only 15 consumers joined the feasibility study, significance testing in this case is very conservative. No significant effects were detected at a $5 \%$ level and one effect was detected at a $10 \%$ level. In order to report on favourable directions to follow in future product development phases, focus will be made on reporting the largest size effects as well as results at a significance level of $20 \%$.

\section{Results and discussion}

\subsection{Characteristics of dried bilberry press cake}

Bilberry press cake qualified as a suitable raw material for drying and subsequent processing since the skin of the berries had already been broken facilitating water removal, and due to low sugar levels after juice separation which reduced stickiness of the berry material. Moisture content, water activity and total phenolic content of the dried materials is presented in Table 1 . HA drying of bilberry press cake at $40{ }^{\circ} \mathrm{C}$ resulted in the longest drying time $(360 \mathrm{~min})$ while for MWHA drying the drying time was $215 \mathrm{~min}$. Hence, MWHA drying enabled a $40 \%$ reduction in drying time compared to HA drying. While HA drying consists of heating from the outside towards the core by convection and conduction, microwave drying is based on internal temperature rise due to electromagnetic heating. In the present study, MWHA drying was used, which is a combination of the two drying techniques. This resulted in more efficient drying than HA drying alone, which reduced the drying time. Also, the additional internal drying achieved using microwaves may have influenced the microstructure of the berry material. After milling, there was an indication that the MWHA dried material contained a larger fraction of small particles than the HA dried material (Fig. 1), which may be due to structural differences between the two materials. The total phenolic content decreased significantly during drying, to a similar extent for both drying techniques. Although the MWHA drying reduced the total drying time, the final content of total phenolics was similar in both materials. This may be due to that heat sensitive phenolics were lost early in the drying process, and prolonged drying (as in the case of HA drying) did not cause further polyphenol losses. However, thermal degradation of polyphenols is in general more common at higher temperatures, as demonstrated by Michalska, Wojdylo, Lech, Lysiak, and Figiel (2017) for black current pomace powder where drying at temperatures ranging from 50 to $90^{\circ} \mathrm{C}$ resulted in a linear decrease in total phenolics but with minor effects at $50^{\circ} \mathrm{C}$. Blueberry polyphenol oxidase, which in the presence of oxygen causes

Table 2

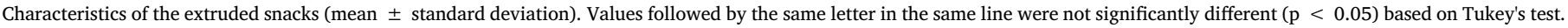

\begin{tabular}{|c|c|c|c|c|c|}
\hline $\begin{array}{l}\text { Extruded snack } \\
\text { characteristics }\end{array}$ & Rye & $\begin{array}{l}\text { Rye }+10 \% \text { Hot air dried } \\
\text { bilberry powder }\end{array}$ & $\begin{array}{l}\text { Rye }+10 \% \text { Microwave assisted } \\
\text { hot air dried bilberry powder }\end{array}$ & $\begin{array}{l}\text { Rye }+25 \% \text { Hot air dried } \\
\text { bilberry powder }\end{array}$ & $\begin{array}{l}\text { Rye }+25 \% \text { Microwave assisted } \\
\text { hot air dried bilberry powder }\end{array}$ \\
\hline $\begin{array}{l}\text { Degree of expansion } \\
\text { (\%) }\end{array}$ & $360 \pm 12^{c}$ & $295 \pm 8^{b}$ & $298 \pm 8^{b}$ & $246 \pm 4^{\mathrm{a}}$ & $246 \pm 7^{\mathrm{a}}$ \\
\hline $\begin{array}{l}\text { Specific density }(\mathrm{kg} / \\
\left.\mathrm{m}^{3}\right)\end{array}$ & $198 \pm 9^{a}$ & $246 \pm 12^{\mathrm{bc}}$ & $245 \pm 14^{\mathrm{c}}$ & $329 \pm 12^{\mathrm{ab}}$ & $335 \pm 16^{\mathrm{bc}}$ \\
\hline Hardness $(\mathrm{N})$ & $48 \pm 4^{\mathrm{a}}$ & $53 \pm 2^{\mathrm{bc}}$ & $57 \pm 5^{c}$ & $51 \pm 3^{\mathrm{ab}}$ & $55 \pm 7^{\mathrm{bc}}$ \\
\hline $\begin{array}{l}\text { Crispness work (N/ } \\
\text { mm) }\end{array}$ & $2.5 \pm 0.3^{\mathrm{a}}$ & $3.0 \pm 0.5^{b c}$ & $3.0 \pm 0.3^{b c}$ & $2.8 \pm 0.5^{\mathrm{ab}}$ & $3.5 \pm 0.5^{c}$ \\
\hline Crispness index & $1.7 \pm 0 \times 10^{-3 \mathrm{~b}}$ & $1.3 \pm 0 \times 10^{-3 a}$ & $1.2 \pm 0 \times 10^{-3 a}$ & $2.5 \pm 0 \times 10^{-3 c}$ & $1.7 \pm 0 \times 10^{-3 \mathrm{~b}}$ \\
\hline $\begin{array}{l}\text { Total phenolic content } \\
\text { (mg/g DW) }\end{array}$ & $0.59 \pm 0.00^{\mathrm{e}}$ & $3.50 \pm 0.05^{d}$ & $3.89 \pm 0.07^{c}$ & $7.40 \pm 0.20^{\mathrm{b}}$ & $7.82 \pm 0.08^{\mathrm{a}}$ \\
\hline
\end{tabular}



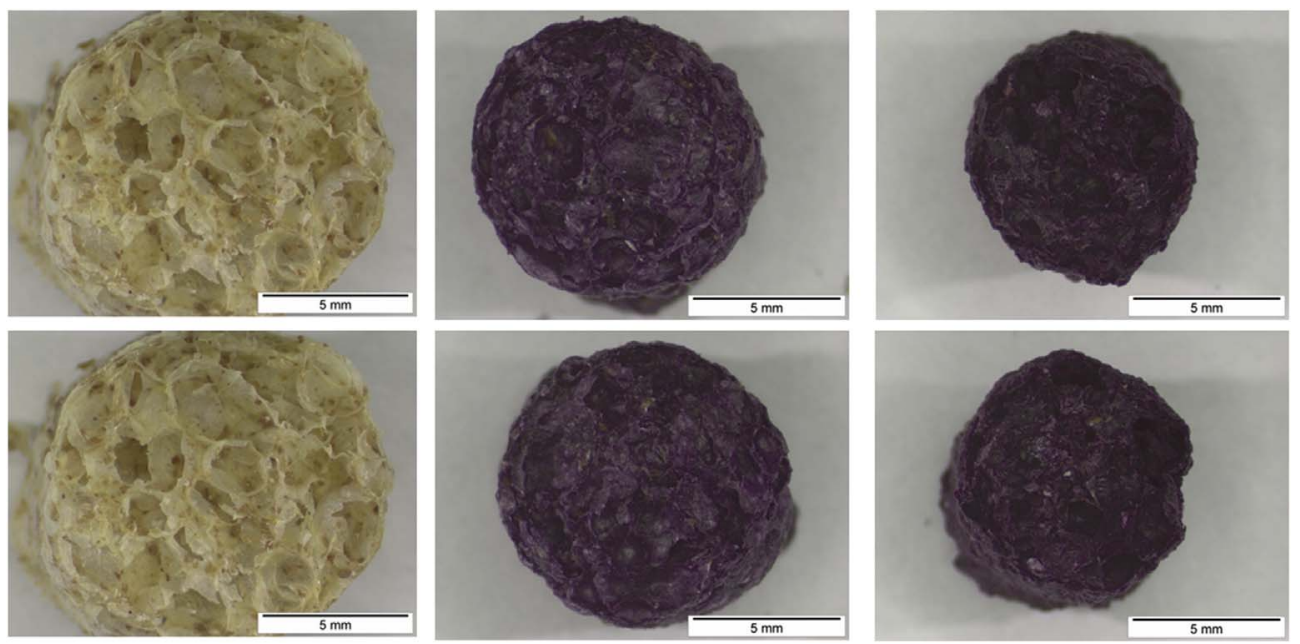

Fig. 2. Stereomicroscope images of radial sections of the extrudates. Reference wholegrain rye flour extrudate with no added press cake (WG); $10 \%$ hot air and microwave assisted hot air dried bilberry press cake added extrudate (10HA and 10MWHA, respectively); $25 \%$ hot air and microwave assisted hot air dried bilberry press cake added extrudate (25HA and 25MWHA, respectively).

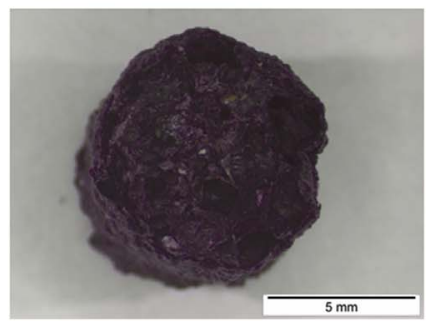

degradation of major polyphenolic compounds has been reported to show activity over a wide temperature range $\left(25-65^{\circ} \mathrm{C}\right)$. In the current study drying at $40^{\circ} \mathrm{C}$ may have enabled enzymatic degradation during the initial drying steps (Siddiq \& Dolan, 2017). Subsequent milling of the dried press cakes did not affect either the moisture content or the total phenolic content.

\subsection{Characteristics of bilberry-wholegrain rye extrudates}

The addition of bilberry press cake powders to the wholegrain rye based formulation caused a significant decrease in the degree of expansion of the wholegrain rye extrudates, indicated by an increase in the specific density from $198 \mathrm{~kg} / \mathrm{m}^{3}$ (wholegrain rye) to 245 and $335 \mathrm{~kg} / \mathrm{m}^{3}$, respectively for $10 \%$ and $25 \%$ bilberry press cake addition (Fig. 2, Table 2). The dietary fibre (DF) content of extrudates was $23.7 \mathrm{~g} / 100 \mathrm{~g}$ ( $8.5 \mathrm{~g} / 100 \mathrm{~g}$ soluble, $15.2 \mathrm{~g} / 100 \mathrm{~g}$ insoluble), $25.8 \mathrm{~g} / 100 \mathrm{~g}$ $(9.1 \mathrm{~g} / 100 \mathrm{~g}$ soluble, $16.7 \mathrm{~g} / 100 \mathrm{~g}$ insoluble), and $27.9 \mathrm{~g} / 100 \mathrm{~g}(9.4 \mathrm{~g} /$ $100 \mathrm{~g}$ soluble, $18.5 \mathrm{~g} / 100 \mathrm{~g}$ insoluble), respectively for wholegrain rye, $10 \%$ and $25 \%$ bilberry press cake added samples. Addition of bilberry press cake powder to wholegrain rye flour significantly increased the insoluble DF, which went through only minor structural changes during extrusion and acted mainly as filler particles that led to structural anisotropy (Fig. 2). A similar phenomenon was observed in the literature when other fruit press cakes (eg. apple, blackcurrant) were utilized as DF sources in starch based extrudates (Karkle, Alavi, \& Dogan, 2012; Mäkilä et al., 2014; O'shea, Arendt, \& Gallagher, 2014; Wang et al., 2017). Addition of DF resulted in inferior structural and textural responses in extrudates as increasing the DF content led to lower expansion, high density, less crispy but rather hard products (Alam et al., 2014, 2017). More than 5-10 g/100 g cherry or grape press cake addition levels caused adverse structural and textural effects (Altan, McCarthy, \& Maskan, 2008; Wang et al., 2017). Insoluble DF was shown to alter the glass transition of the melt due to high hydrophilicity and increased water absorption (O'shea et al., 2014). Specific mechanical energy refers to the level of energy per mass unit that is transferred to the material by mechanical input during extrusion. The SME value was $0.27,0.17$ and $0.13 \mathrm{kWh} / \mathrm{g}$ for wholegrain rye flour, $10 \%$ and $25 \%$ bilberry press cake supplemented rye flour, respectively. The gradual decrease in SME values might be related to the gradual increase in moisture content (from 11 to $12.5 \mathrm{~g} / 100 \mathrm{~g}$ ) with the increase in bilberry press cake addition amount (from 0 to 25\%) but also with the gradual reduction in starch content whilst increasing the bilberry press cake and in turn insoluble dietary fibre content. Extrudate expansion is strongly influenced by biopolymer interactions and melt rheology (Sozer \& Poutanen, 2013, pp. 256-272). In order to achieve a well-expanded extruded matrix, the shear viscosity of the melt should be low enough for growth of air cells and further expansion, but high enough to inhibit collapse of air cells (Pai, Blake, Hamaker, \& Campanella, 2009). The incorporation of inert insoluble particles such as the IDF in bilberry press cake might have reduced the starch viscosity at constant melt temperature. This might led to reduced mechanical starch transformation in the extruder due to reduced SME which will further result in dense, hard and less crispy textures.

The addition of bilberry press cake powder increased both the hardness and crispiness work regardless of addition level. The crispiness index was the highest for $25 \%$ HA bilberry press cake powder (Table 2). Differences in microstructure between HA and MWHA dried press cake may have affected the melt properties during extrusion processing. The consumer evaluation reports variations in texture corresponding to the above physical measurements (Fig. 3). On average, extruded products with addition of $10 \%$ bilberry press cake powder were described to have a more enjoyable texture (mean score 6.2 on the 9-point hedonic scale) than products with addition of $25 \%$ bilberry press cake powder (mean score 5.3) (Fig. 3a). More specifically, 10\% addition of bilberry press cake powder resulted in properties of porosity and hardness closer to the consumers' ideal point on average. These samples presented a more porous (mean JAR score $5.5 ; \mathrm{p}=0.20$ ), less crispy (mean JAR score $5.7, \mathrm{p}=0.08$ ) and less hard (mean JAR score 4.7; p = 0.13) texture than for the extrudates with $25 \%$ addition of bilberry powder (porosity mean JAR score: 4.1, i.e. somewhat not porous enough; crispy mean JAR score: 5.4; hardness mean JAR score: 5.9, i.e. somewhat too hard) (Fig. 3b). Consequently, the decrease in degree of expansion and increase in density, which was proportional to bilberry press cake powder addition, was perceived by the consumers as decreased porosity and increased hardness. Attribute stickiness showed very little variation between samples, with an overall mean of 5.6 on the JAR scale (Fig. 3b). Visual appearance and taste were moderately acceptable for all extrudates with average scores around the hedonic scale's mid-point (Fig. 3a). However, the extrudates from HA process scored slightly better in overall liking (mean score: $5.8 ; \mathrm{p}=0.16$ ), than did the extrudates with MWHA process (mean score: 5.2) (Fig. 3a). HA drying also tended to be preferred to MWHA drying in terms of visual appearance $(p=0.17)$ and to lead to lower crispness perception $(\mathrm{p}=0.11)$. All in all, the bilberry press cake enriched extrudates were considered moderately palatable by the subjects and the concept of a healthier cereal based snack was regarded as positive. Due to the very small size of the panel, the directions of preferences reported here are only indicative and supportive of the feasibility study. Further consumer tests targeted at the market population will be necessary in future stages of the product development process. At this stage, the relationship between the panel's evaluations and the processing parameters are valuable inputs for further texture management of 


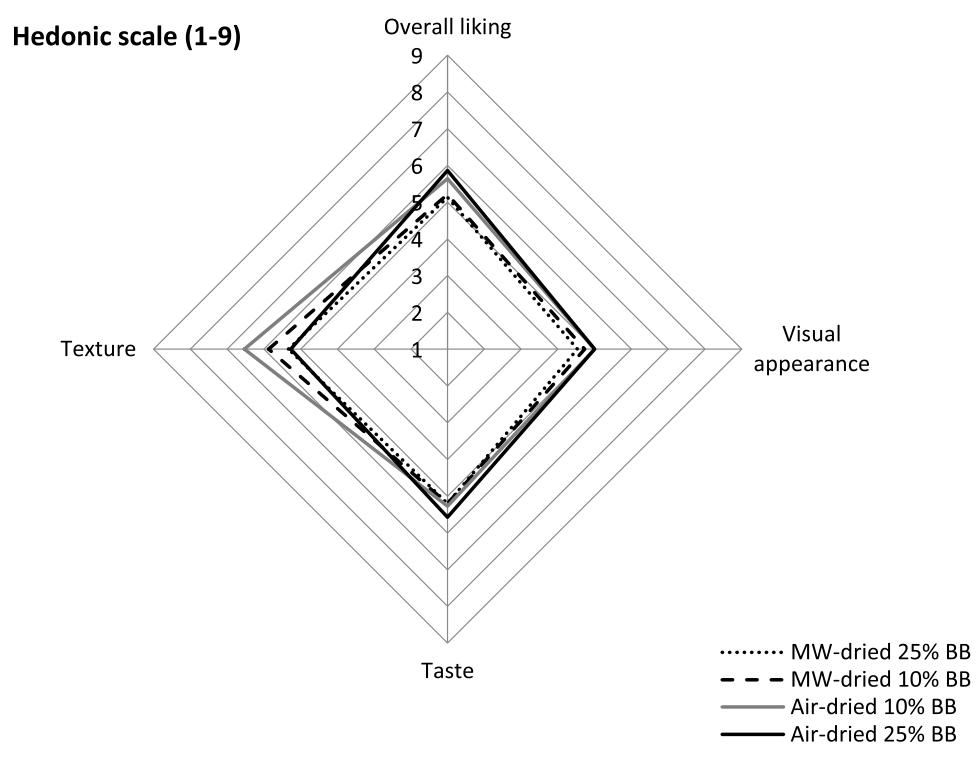

Texture attributes evaluated by just-about-right scale

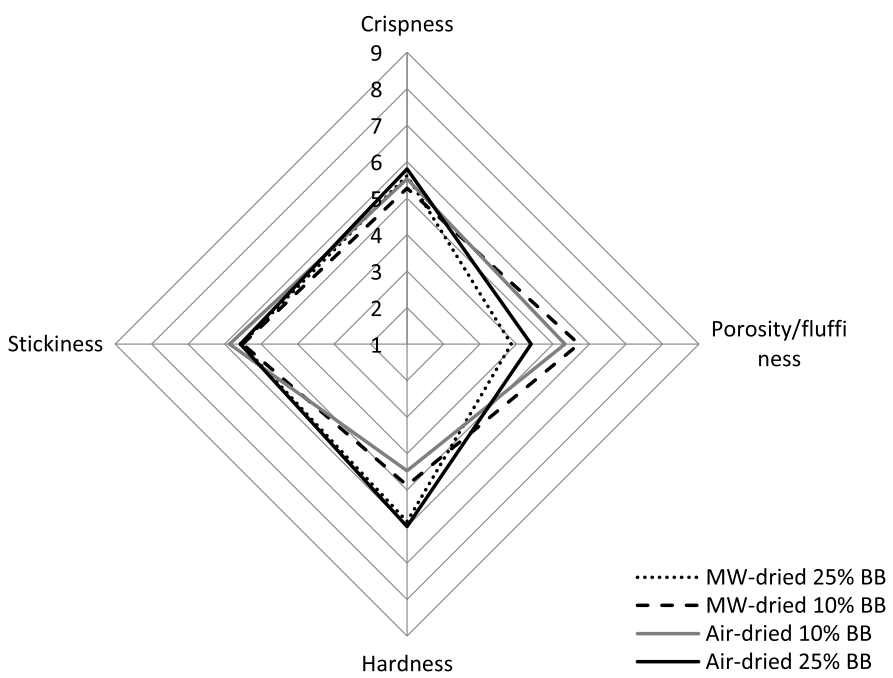

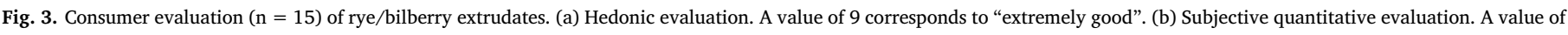
5 corresponds to "just about right".

puffed extrudates containing berry materials. Lipids in berry seeds may cause problems with oxidation in products, which could be more prominent in the extrudates with high bilberry press cake addition levels. However, no negative effects on taste or overall liking were seen for extrudates with $25 \%$ addition compared to $10 \%$ addition. The press cake contained large amounts of seeds. Some of these seeds were broken during milling, but many stayed intact (visual observation). Although extrusion processing of bilberry press cake caused a significant reduction in the total phenolics content; it also caused a dramatic increase in total phenolics of puffed extrudates in proportion to the addition level (Tables 1 and 2). The overall decrease in total phenolics might be a result of decarboxylation due to combined high temperature and moisture during extrusion (Brennan, Brennan, Derbyshire, \& Tiwari, 2011). The total phenolic content was slightly higher in extruded snacks with MWHA dried bilberry powders compared with snacks containing HA dried bilberry powders $(\mathrm{p}<0.05)$. The observed differences in total phenolic content may be related to different extractability of phenolic compounds due to microstructural differences between HA and MWHA dried press cake.

\section{Conclusions}

Mild drying and extrusion processing of side streams from berry juice production enables retention of valuable compounds in the food chain and reduced waste production. This study showed that powder of bilberry press cake could be incorporated in cereal based extruded snacks with acceptable appearance, taste and texture as well as enhanced phenolic content. This is a promising way to provide healthy low-fat snack products rich in dietary fibres and polyphenols. Different drying techniques implied a difference in processing time $(40 \%$ reduced drying time with MWHA drying). However, the retention of total phenolics and physical characteristics were similar for snacks extruded from bilberry powders produced with different drying techniques. Further studies of the combination of drying techniques and extrusion 
on the sensory characteristics and health-beneficial compounds remaining in bilberry press residues and extrudates are needed.

\section{Acknowledgements}

The authors acknowledge the financial support for this project provided by transnational funding bodies, being partners of the FP7 ERA-net project, CORE Organic Plus, and with cofunds from the European Commission.

\section{References}

Alam, S. A., Järvinen, J., Kirjoranta, S., Jouppila, K., Poutanen, K., \& Sozer, N. (2014) Influence of particle size reduction on structural and mechanical properties of extruded rye bran. Food and Bioprocess Technology, 7, 2121-2133.

Alam, S. A., Pentikäinen, S., Närväinen, L., Holopainen-Mantila, U., Poutanen, K., \& Sozer, N. (2017). Effects of structural and textural properties of brittle cereal foams on mechanisms of oral breakdown and in vitro starch digestibility. Food Research International, 96, 1-11.

Altan, A., McCarthy, K. L., \& Maskan, M. (2008). Twin-screw extrusion of barley-grape pomace blends: Extrudate characteristics and determination of optimum processing conditions. Journal of Food Engineering, 89, 24-32.

Barnes, J. S., Nguyen, H. P., Shen, S., \& Schug, K. A. (2009). General method for extraction of blueberry anthocyanins and identification using high performance liquid chromatography-electrospray ionization-ion trap-time of flight-mass spectrometry. Journal of Chromatography A, 1216, 4728-4735.

Brennan, C., Brennan, M., Derbyshire, E., \& Tiwari, B. K. (2011). Effects of extrusion on the polyphenols, vitamins and antioxidant activity of foods. Trends in Food Science \& Technology, 22, 570-575.

Dinkova, R., Shikov, V., Mihalev, K., Velchev, Z., Dinkov, H., \& Mollov, P. (2012). Changes in the total anthocyanins and polyphenols during processing of wild berries into freshly pressed juice. Proceeding of BIOATLAS 2012 Conference (pp. 254-259). .

Figuerola, F. E. (2007). Dehydration of berries. In Y. Zhao (Ed.). Berry fruit Value-added products for health promotion. Boca Raton: CRC Press.

Grzelak-Blaszczyk, K., Karlinska, E., Grzeda, K., Roj, E., \& Kolodziejczyk, K. (2017), Defatted strawberry seeds as a source of phenolics, dietary fibre and minerals. LWT Food Science and Technology, 84, 18-22.

Gustavsson, J., \& Stage, J. (2011). Retail waste of horticultural products in Sweden. Resources, Conservation and Recycling, 55, 554-556.

Heidenreich, S., Jaros, D., Rohm, H., \& Ziems, A. (2004). Relationship between water activity and crispness of extruded rice crisps. Journal of Texture Studies, 35, 621-633.

Howard, L. R., Clark, J. R., \& Brownmiller, C. (2003). Antioxidant capacity and phenolic content in blueberries as affected by genotype and growing season. Journal of the Science of Food and Agriculture, 83, 1238-1247.

Hu, L., Hsieh, F., \& Huff, H. (1993). Corn meal extrusion with emulsifier and soybean fiber. LWT - Food Science and Technology, 26, 544-551.

Jangam, S. V., Law, A. S., \& Mujumdar, A. S. (2010). Basic concepts and definitions. In S. V. Jangam, C. L. Law, \& A. S. Mujumdar (Vol. Eds.), Drying of foods, vegetables and fruits: Vol. 1, (pp. 1-30). Singapore.

Karkle, E. L., Alavi, S., \& Dogan, H. (2012). Cellular architecture and its relationship with mechanical properties in expanded extrudates containing apple pomace. Food Research International, 46, 10-21.
Kerbstadt, S., Eliasson, L., Mustafa, A., \& Ahrné, L. (2015). Effect of novel drying techniques on the extraction of anthocyanins from bilberry press cake using supercritical carbon dioxide. Innovat. Food Sci. Emerg. Technol. 29, 209-214.

Kryeviciute, N., Kraujalis, P., \& Venkutonis, P. R. (2016). Optimization of high pressure extraction processes for raspberry pomace inot lipohilic and hydrophilic fractions. The Journal of Supercritical Fluids, 108, 61-68.

Lawless, H. T., \& Heymann, H. (2010). Acceptance testing. Sensory evaluation of food (pp. 325-347). New York: Springer.

MacFie, H. J., Bratchell, N., Greenhoff, K., \& Vallis, L. V. (1989). Designs to balance the effect of order of presentation and first-order carry-over effects in hall test. Journal of Sensory Studies, 4, 129-148.

Mäkilä, L., Laaksonen, O., Diaz, J. M. R., Vahvaselkä, M., Myllymäki, O., Lehtomäki, I., et al. (2014). Exploiting blackcurrant juice press residue in extruded snacks. LWTFood Science and Technology, 57, 618-627.

Michalska, A., Wojdylo, A., Lech, K., Lysiak, G. P., \& Figiel, A. (2017). Effect of different drying techniques on physical properties, total polyphenols and antioxidant capacity of blackcurrant pomace powders. LWT - Food Science and Technology, 78, 114-121.

Mikulic-Petkovsek, M., Schmitzer, V., Slatnar, A., Stampar, F., \& Veberic, R. (2015). A comparison of fruit quality parameters of wild bilberry (Vaccinium myrtillus L.) growing at different locations. Journal of the Science of Food and Agriculture, 95 $776-785$.

O'shea, N., Arendt, E., \& Gallagher, E. (2014). Enhancing an extruded puffed snack by optimising die head temperature, screw speed and apple pomace inclusion. Food and Bioprocess Technology, 7, 1767-1782.

Pai, D. A., Blake, O. A., Hamaker, B. R., \& Campanella, O. H. (2009). Importance of extensional rheological properties on fiber-enriched corn extrudates. Journal of Cereal Science, 50, 227-234.

Pojer, E., Mattivi, F., Johnson, D., \& Stockley, C. S. (2013). The case for anthocyanin consumption to promote human health: A review. Comprehensive Reviews in Food Science and Food Safety, 12(5), 483-508.

Sibakov, J. K., Kirjoranta, S., Alam, S. A., Kokkonen, H., Jurvelin, J. S., Jouppila, K., et al. (2015). Effect of oat bran fractions on extrudates made of defatted oats. Food and Bioprocess Technology, 8, 445-458.

Siddiq, M., \& Dolan, K. D. (2017). Characterization and heat inactivation kinetics of polyphenol oxidase from blueberry (Vaccinium corymbosum L.). Food Chemistry, 218, 216-220.

Sozer, N., \& Poutanen, K. (2013). Fibre in extruded food products. In J. A. Delcour, \& K. Poutanen (Eds.). Fibre-rich and wholegrain foods - improving quality. Cambridge: Woodhead Publishing.

Struck, S., Plaza, M., Turner, C., \& Rohm, H. (2016). Berry pomace - a review of processing and chemical analysis of its polyphenols. International Journal of Food Science and Technology, 51, 1305-1318.

Van Buggenhout, S., Ahrné, L., Alminger, M., Andrys, A., Benjamin, M., Bialek, L., et al. (2012). Structural design of natural plant-based foods to promote nutritional quality. Trends in Food Science \& Technology, 24, 47-59.

Van Hecke, E., Allaf, K., \& Bouvier, J. (1998). Texture and structure of crispy-puffed food products part II: Mechanical properties in structure. Journal of Texture Studies, 29, 617-632.

Wang, S., Kowalski, R. J., Kang, Y., Kiszonas, A. M., Zhu, M. J., \& Ganjyal, G. M. (2017). Impacts of the particle sizes and levels of inclusion of cherry pomace on the physical and structural properties of directs expanded corn starch. Food and Bioprocess Technology, 10, 394-406.

Zielinska, M., \& Michalska, A. (2016). Microwave-assisted drying of blueberry (Vaccinium corymbosum AL.) fruits: Drying kinetics, polyphenols, anthocyanins, antioxidant capacity, colour and texture. Food Chemistry, 212, 671-680. 